\title{
Development and Validation of Superstitious Beliefs Scale
}

\author{
Surekha Chukkali ${ }^{1} \&$ Anjali M Dey ${ }^{2}$ \\ 'Department of Psychology, Christ (Deemed to be University) Delhi-NCR. \\ Email: surekha.chukkali@christuniversity.in \\ ${ }^{2}$ Research Scholar, Center for Research, Christ (Deemed to be University)
}

\begin{abstract}
Superstitions though considered as irrational beliefs are widely prevalent in all cultures. Most of the existing work on superstitions are predominantly based on traditional western beliefs. The relevance of established superstition scales which are developed in western societies in collective societies need to explored. Interdependent nature of self which is a characteristic of collectivistic culture also has a role in belief formation. The present study aims at developing a new self-report measure of superstitious beliefs scale. Study 1, focused on exploring the factor structure and establishing reliability over a sample of 338 undergraduate students. The 17 -item Superstitious Belief Scale (SBS) developed distinguishes a six-factor structure namely, Popular Beliefs, Belief in Good Luck, Belief in Bad Luck, Personal Superstitions and Social Superstitions. The six-factor structure was evaluated on a new sample $(\mathrm{N}=483)$ using confirmatory factor analysis in Study 2. The internal consistency values of the new SBS over Studies 1 and 2 indicated high reliability. The findings have important implications for existing theory on superstitions. The new framework proposes and demonstrates the need to base the understanding of measurement of superstitious beliefs relevant in India.
\end{abstract}

Keywords: superstitious beliefs, good luck, bad luck, scale, factor structure

\section{Introduction}

A superstition is a widespread phenomenon which has fascinated philosophers and researchers alike. Over a period of time, superstitions have demonstrated a strong presence across all societies (Fidrmuc \& Tena, 2015; Kramer \& Block, 2008; Vyse, 1997; Parida, 1962; Saenko, 2005). They are often referred to as false or irrational beliefs (Jahoda, 1968; Vyse, 1997). Researchers have attempted to offer better understanding and explanations of the phenomenon of superstition; however, research in this area is minimal. Few of the characteristics of the concept of superstition given by Levitt (1952) still holds true wherein it is suggested that superstition is fundamentally irrational, widely and popularly accepted and impacts the behavior of the beholder.

Superstitions are prevalent among the general population. Superstitious beliefs are widespread among individuals with lower education levels as well as highly educated individuals (Sumaranjitha \& Sreedhar, 1992).Various studies explored the variations based on gender (Aarnio \& Lindeman, 2005; Lewis \& Gallagher, 2001; Mullick, Khalifa, Nahar, \& Walker, 2013; Tobacyk \& Milford, 1983; Dag, 1999), age groups (Ben-Yehuda, 1985; Gallup, 1996; MacDonald, 1995; Malinowski, 1927, 1948; Peltzer, 2003; Torgler, 2007), education (Barro \& McCleary, 2002; Blum, 1976; Mowen \& Carlson, 2003; Orenstein, 2002; Otis \& Alcock, 1982; Peltzer, 2003; Ramezani,

(c) AesthetixMS 2020. This Open Access article is published under a Creative Commons Attribution Non-Commercial 4.0 International License (http://creativecommons.org/licenses/by-nc/4.0/), which permits non-commercial re-use, distribution, and reproduction in any medium, provided the original work is properly cited. For citation use the DOI. For commercial re-use, please contact editor@rupkatha.com. 
Ramezani, \& Ramezani 2016; Tobacyk, 1984), socio economic status (Emadi, 2005; Farooq \& Kayani, 2012; Shrivastav \& Kotnala, 2015; Stark \& Bainbridge, 1980) and religious beliefs (Barro \& McCleary, 2002; Burhmann \& Zaug, 1981; Gallup, 2005; Orenstein, 2002; Tobacyk \& Milford, 1983; Torgler, 2007, 2003).

Interest in measuring superstitions is evident over the years as they not only seemed to affect daily activities but also made a difference in businesses, market economy, buying behavior and even medicine (Ang, Lai \& Leong, 2014; Antipov \& Pokryshevskaya, 2015; Block \& Kramer, 2009; Botha, 2013; Frotin, Hill, \& Huang, 2014; Fu \& Viard, 2011; Hirschleifer, Jian, \& Zhang, 2011; Kolb \& Rodriguez, 1987; Lindeman \& Saher, 2007; Shum, Sun \& Ye, 2014). There were attempts at measuring sports superstitions (Barkoukis, Perkos, \& Kokkinopoulos, 2011; Bleak \& Frederick, 1998; Brevers, Dan, Noel, \& Nils, 2011; Buhrmann \& Zaugg, 1981; Ofori, Tod, \& Lavallee, 2017; Todd \& Brown, 2003). Sportspersons practice certain individual ritualistic behaviors (Archetti, 1999; Birrell, 1981) as well as team practices (Ofori, Biddle, \& Lavallee, 2012). Superstitious beliefs are also practiced by them to deal with stressful situations and to enhance performance (Maranise, 2013). Past studies indicate that superstitious beliefs positively predict a diverse range of psychological outcomes such as enhanced performance, regained sense of control (Bleak \& Frederick, 1998; Burger \& Lynn, 2005; Damisch, Stoberock, \& Mussweiler, 2010; Irwin, 1993; Malinowski, 1948; Presson \& Benassi, 1996; Zhang, Risen, \& Hosey, 2013), proper negotiation of social and emotional problems (Subbotsky, 2004) and achievement of self efficacy (Damisch, Stoberock, \& Mussweiler, 2010).

There are various explanations of superstition in literature. Superstitions are often understood as beliefs which do not confirm with the scientific explanation (Peterson, 1978). Superstitions were initially studied in the context of paranormal beliefs (Dresslar, 1907; MacDonald, 1995; Tobacyk, 1984). However, they are now considered as distinct from paranormal and religious beliefs (Beck \& Miller, 2001; MacDonald, 1995; Peterson, 1978; Tobacyk \& Milford, 1983). A causal relationship is perceived and established even in the absence of scientific explanation and contrary evidence (Hanks, Zhang, \& McGinley, 2016; Tobacyk \& Shrader, 1991). Superstitions are also considered as different from religious beliefs (Campbell, 1996; Czech, Wrisberg, Fisher, Thompson, \& Hayes, 2004; Delacroix \& Guillard, 2008; Hoffman, 2010; Kreider, 2003; Lawrence, 2005; Maranise, 2013; Miller, 2008; Murray, Joyner, Burke Wilson, \& Zwald, 2005; Price, 2009; Storch et al., 2008; Watson \& Czech, 2005) though many researchers also studied both under a single umbrella (Beck \& Miller, 2001; MacDonald, 1995; Orenstein, 2002; Tobacyk \& Milford, 1983). Superstition is also viewed as erroneous ideas about reality (Beck \& Forstmeier, 2007) and as illusory irrational correlations (Haselton \& Nettle, 2006). In the recent years, superstitious beliefs are understood in terms of luck beliefs (Brevers, Dan, Noel, \& Nils, 2011; Fluke, Webster, \& Saucier, 2014; Mundada, 2013; Wiseman \& Watt, 2004). Luck is viewed as a preferred term to explain superstition than terms like fortune (Ranieri, 2015).

Earlier accounts of superstitions focused on uncertainty and fear as the driving factors (Malinowski, 1948). Superstitions were also assumed to be the result of higher levels of motivation for individuals to predict and control one environment. Superstition and luck are indissolubly connected. Superstitions are often understood as beliefs intended to alter one's luck (Kramer \& Block, 2011). Superstitions are also understood as erroneous causal links between two completely independent events (Foster \& Kokko, 2009), as beliefs which are not consistent with scientific knowledge (Stanke, 2004). The underlying assumption of all the explanations of superstition is the tendency of the individual to think of the existence of causal relationship when there is no scientific one (Hanks, Zhang, \& McGinley, 2016). 
One of the earlier and more popular scales used to measure superstitious beliefs is the superstition subscale of widely popular Paranormal Belief Scale by Tobacyk and Milford (1983). It mainly explored negative superstitions related to bad luck or detrimental outcomes. Positive and negative superstitions can have a varied impact. Belief in superstition scale is a six-item measure subsequently, developed by Wiseman and Watt, 2004 to measure positive and negative superstitions. However, they did not discuss information on internal consistency. Superstition scale items should ideally measure few popular superstitious beliefs prevalent in specific cultures and also certain general orientations on beliefs in good and bad luck. It is considered as important to assess general propensity to follow superstitious behavior through positive and negative outcome focused items (Fluke et al., 2014). Revised Belief in superstition scale developed by Fluke et al., (2014) is an improvised measure of Belief in superstition scale (Wiseman \& Watt, 2004). It explored the third component of superstitious beliefs namely belief related to change in luck. The theoretical framework suggested by Fluke et al., (2014) underline the importance of taking into account both positive beliefs, negative beliefs, and beliefs that one can work on changing luck. However, relevance of positive and negative beliefs and their associations with the prevalent culture is not understood. There is a need for exploring the nature of superstitious beliefs held by people in individualistic and collectivistic cultures.

Superstition is also considered a cultural phenomenon with relativity. Many superstitious beliefs can exist in a particular culture. Specific superstitions differ across cultures (Carlson, Mowen, \& Fang, 2009). Though the existing measures of superstitious beliefs are valid and reliable, they were notably developed in western contexts. Superstitious beliefs may be location specific and there is a need to consider how these beliefs are developed and demonstrated in Indian context.

The beliefs which individuals hold and the resulting behavior can be understood from an independent and interdependent construal perspective (Markus \& Kitayama, 1991). According to this perspective, an individual's behavior is determined to a greater extent on what they perceive to be are the thoughts, feelings, and actions of others in their social context. Unlike the individualistic societies, where there is an emphasis on autonomy and self-set goals, collectivist societies promote interdependence and cooperation among family members (King \& McInerney, 2012; Markus \& Kitayama, 1991). Individuals do not exist in isolation. Family members are more intimate and caring towards each other. The family becomes a central pillar in their social structure. Goals set, beliefs formed and decisions taken by individual members of the family are often in the context of family functioning. The dynamics of the family are also understood in the context of their societal and cultural background (Chaddha \& Deb, 2013; McGill, 1983). Tolerance for ambiguity and contradictions and a lower preference for cognitive consistency are also assumed of individuals in collectivist societies (Peng \& Nisbett, 1999). Therefore, it is important to understand the relevance of social norms in superstitious beliefs for individual members in a society. Superstitious beliefs scales should have a component which explores the social aspect of these beliefs.

\section{The Present Research}

India is one of the more populous nation and a significant rising economic power. Prevalence of superstitious beliefs In India need to explored for scientific growth and development. In Indian context, social cohesion and interdependence have greater prominence than in the western countries (Chaddha \& Deb, 2013). We intend to develop a Superstitious Beliefs Scale which builds upon previous work of Wiseman and Watt (2004) and furthered by Fluke et al., (2014) and which 
incorporates superstitious beliefs relevant for Indian society. The framework proposed by Weisman and Watt (2204) is widely accepted and its relevance in Indian context will be explored. Firstly, we developed a scale of superstitious belief and examined its factor structure by means of exploratory factor analysis (Study 1). We then validated the dimensionality in Study 2 using confirmatory factor analysis and assessed the construct validity of the scale by administering five other scales.

\section{Study 1}

The objective of study 1 was to examine the dimensionality of the new Superstitious Beliefs Scale using exploratory factor analysis.

\section{Method}

Participants. 338 undergraduate students pursuing social sciences (age: $\mathrm{M}=18$ years, $\mathrm{SD}=1.03$ ) from a large southern university in India participated in this study. $60 \%$ of the participants were females $(n=202)$. Participants were compensated with class credit.

Procedure and Material. The target audience was informed about the research through classroom announcements. Consent was taken before they were administered the superstition scale. Participants were requested to give their responses on a 5-point scale of their feelings on items such as "Good luck charms help bring good luck". The Likert scale ranges from 1 (strongly disagree) to 5 (strongly agree). A higher score signifies higher levels of belief in superstitions.

Development of Superstitious Beliefs Scale. To develop superstitious beliefs scale, we developed an initial item pool of 41 statements. Our overarching goal for scale development was to capture the beliefs and behaviors characteristic of a superstitious person. Few of the initial items were developed based on the existing literature (Fluke et al., 2014; Wiseman \& Watt, 2004). Items from existing scales predominantly measured specific superstitious beliefs (Tobacyk \& Milford, 1983; Wiseman \& Watt, 2004), but few scales had general belief items about luck as well (Fluke et al., 2014). However, the relevance of items need to be explored. Avoiding walking under a ladder and knocking on wood for good luck are common specific beliefs held by people in the west but are not majorly held in Indian cultural context. Family and society also have a predominant role in the development of beliefs in India. The item pool developed initially incorporated few popular superstitious beliefs in India (eg "It is bad luck to cut your nails on particular days"), general beliefs about luck and items reflecting the interdependence nature of superstitious beliefs and behaviors (eg "I practice certain good luck/bad luck rituals because they are prevalent in my community").

The items were reviewed by the researcher for redundancy and simplicity. Items which had long sentences and vague were eliminated as it decreases readability (DeVellis, 2012). Eight items were eliminated at this stage from the initial pool. Ten academic experts from the background of psychology, sociology and anthropology evaluated the remaining thirty-three item scale for content validity. The evaluations were calculated through content validity index using a three-point criteria (1-accept the item; 2-accept with modifications; 3-reject the item). All the items which had greater than $80 \%$ agreement among the judges were retained.

Two items did not meet the criteria and were rejected subsequently. Two other items were revised based on specific feedback to improvise on the clarity of items. The remaining thirty one items constituted the final scale. We subsequently examined the 31 retained items by instructing the participants to mark their responses for each item on the scale. Content analysis of items, 
performed by computing the item-total correlation values revealed an item with very low item-total correlation. After deleting the item, all the other items revealed a correlation distribution ranging from .26 to .70 .

\section{Results}

Exploratory factor analysis done by means of principal component analysis through Promax rotation revealed six factors for the 30 items. Bartlett's test of sphericity is used to check if correlations were suitable for conducting factor analysis. A $\chi^{2}$ value of 14362.112 revealed that correlations were acceptable for factor extraction. Kaiser-Meyer-Olkin (KMO) measure is applied to test the assumption of sampling adequacy. KMO values above .9 are considered superb, between 0.8 and 0.9 as great, between 0.7 and 0.8 as good and values between 0.5 and 0.7 as mediocre (Hutcheson \& Sofroniou, 1999). The KMO value for the present study was 0.93 which indicates adequacy of the sample.

Factors with Eigen-values greater than 1 were retained and it resulted in six-factor solution explaining $62.38 \%$ variance. The total percentage of variance explained by factor solution is important. $60 \%$ of the total item variance is considered a minimum acceptable criterion (Hinkin, Tracey \& Enz, 1997). Eigenvalues help determine the number of factors to be extracted. Usually, factors which have Eigenvalues greater than 1 are retained as they explain significant variance (Tabachnick \& Fidell, 2013). An examination of scree plot also suggested six factors. A criterion of o.40 levels is commonly used to consider a factor as meaningful (Hinkin, Tracey \& Enz, 1997). From the extracted six factors, only the items which loaded 0.40 or more on one factor and which did not cross-load on any other factor were retained for further revision. Twenty four items qualified based on this criterion (Table 2).

Seven items loaded onto the first dimension were identified as Popular Beliefs $(\alpha=.78)$. These items reflected popular superstitious beliefs held by people in India. Five items loaded onto the second dimension which is the belief in positive superstitions. The third dimension identified is the belief in negative superstitions and four items loaded onto this dimension. Three items loaded onto the fourth dimension which is the belief that one can work towards change in luck. The fifth dimension consisting of three items reflected individual superstitious actions, and the sixth dimension having two items revealed social superstitious actions. Scale brevity is an important concern. An optimal tool is usually considered as one which contains few items but also retains its reliability and validity (Stones et al., 1996). Hence, it was decided to retain the top three items from each of the factors for the final version leading to 17-item scale (Table 2). Only two items loaded onto the last dimension. A minimum of three items is usually required to accept a factor in any multidimensional scale. However, scales which have more than one factor can be identified with even two items per factor (Raubenheimer, 2004). Researchers can retain a factor if it can be interpreted in a meaningful way. For constructs with a narrow scope, evidence suggests that twoitem scales can be sufficient (Yong \& Pearce, 2013). Hence the dimension was retained as it was considered meaningful and essential towards the interdependent conceptualization of superstitious beliefs.

The reliability of the overall scale was calculated by Cronbach's alpha coefficient. The reliability value for Superstitious Beliefs Scale (SBS) is .87 indicating very good internal consistency (DeVellis, 1991). The reliability of all the six dimensions ranged from 0.64 to 0.82 (Table 2). The alpha for Factor 1-Popular Beliefs was .78, Factor 2 - Belief in Good Luck was .74, Factor 3-Belief in Bad Luck was.70, Factor 4-Belief that Luck can Change was .64, Factor 5- Personal Superstitious Behaviors was .73 and Factor 6- Social Superstitious Behavior was.82. Five of the alpha coefficients 
were above .7 again indicating good internal consistency (Nunnally, 1978). Although the $\alpha$ for the fourth dimension is .64 , it is considered common for dimensions with fewer items to have lower reliability coefficients (Carmines \& Zeller, 1979; Pallant, 2007). The scale was re-administered on a sample of 70 participants from Study1 and the test-retest reliability coefficient was observed to be high $(\mathrm{r}=.902, \mathrm{p}<.01)$.

Table 2 shows means, corrected item-total correlations, and item discrimination index. To appraise the reliability of the individual item, corrected item-total correlation is taken into consideration. It is a measure which indicates the extent to which an item correlates with total items in the questionnaire, excluding the specific item (DeVellis, 2003). The corrected item-total correlations were above the required cut-off suggested by Field (2009). All the items have values above .30. The distribution of item discrimination index ranged from .30 to.82. Values greater than or equal to.20 are considered acceptable for item discrimination index.

\section{Discussion}

The results from Study 1 indicate empirical evidence that the Superstitious Beliefs Scale is psychometrically sound. The scale demonstrated a high degree of reliability. The 17-item superstitious belief questionnaire is a comprehensive instrument to assess the superstitious beliefs among the Indian population. The results from Study 1 revealed that Superstitious Beliefs Scale demonstrated a model consisting of six dimensions of Popular Beliefs, Belief in Good Luck, Belief in Bad Luck, Belief that Luck can Change, Personal Superstitious Behaviors and Social Superstitious Behaviors.

Few of the items in SBS were sourced from existing scales by Wiseman \& Watt (2004) and Fluke et al., (2014). As a result, the dimension of Belief in Good Luck, Belief in Bad Luck and Beliefs that Luck can Change identified in SBS are same as the original scale. The first dimension identifies few of the popular superstitious beliefs which are relevant to Indian cultural context. It is interesting to note that the items reflect a mix of universal beliefs which are held across different cultural contexts as well as beliefs relevant at the regional context. The item "a black cat passing your path brings bad luck" is a universal belief whereas the item "It is bad luck to cut one's nails on particular days" is more relevant at regional context. The fourth and fifth dimensions support the framework put forward by the present research explaining superstitious beliefs as an interaction of independent and interdependent nature of self. The next step was to cross-validate the proposed factor structure in a new sample.

\section{Study 2}

The objective of the second study was to verify the factor structure of the Superstitious Beliefs Scale developed in Study 1 by using confirmatory factor analysis and to test its validity.

\section{Method}

Participants. For confirmatory factor analysis, 483 undergraduate and postgraduate students pursuing social sciences (age: $M=21$ years, $S D=2.07$ ) from the same university as study 1participated in this study. $62 \%$ of the participants were females $(n=268)$. Participants were compensated with class credit. Further, to test the validity of the scale, the responses of 160 participants (age: $\mathrm{M}=\mathbf{2 2}$ years, $\mathrm{SD}=\mathbf{2 . 0 7}$ ) on Superstitious Beliefs Scale, who were part of the same study were considered for analysis. $53 \%$ of the participants in validity study were females $(n=84)$. 


\section{Procedure and Material.}

The 17- item Superstitious Beliefs Scale developed in the previous phase was administered to confirm the hierarchical model of superstitious beliefs. The target audience was informed about the research being conducted through announcements. Consent of the participants was taken before they were administered the superstition scale. Instructions for responding on a 5-point Likert scale were given similar to Study 1.

For establishing the validity, 160 participants were administered other measures along with Superstitious Beliefs Scale. Pre-established measures of superstitious beliefs and measures of constructs which are considered to be theoretically related to superstitious beliefs were administered. We administered the following scales to explore the construct validity.

Superstitious Beliefs Scale. The 17-item scale developed in study 1 and confirmed through CFA in study 2 was used to examine its validity. Instructions for responding on a 5-point Likert scale, similar to the instructions given in study 1 and 2 were given.

Revised belief in superstition scale. The scale is developed by Fluke et al., (2014) and is a self-report measure constituting nine items and divided into three subscales namely Belief in Bad Luck, Belief in Good Luck and Belief that Luck can Change. This is a revised scale which builds on prior work by Wiseman and Watt's (2004). The statements are rated on a 9-point Likert scale which varied from 1 (strongly disagree) at one end to 9 (strongly agree) on the other end. The reliability of the Positive Superstition subscale is .68, the reliability of Negative Superstition is .75 and .65 is the reliability of Change Luck scale.

Belief in superstition scale. The scale developed by Wiseman and Watt (2004) consists of six items measuring two dimensions of Positive and Negative Superstitions. Positive Superstitions subscale had three items and measured popular superstitions related to positive outcomes or beliefs about good luck. Negative Superstitions subscale also had three items but measuring popular superstitions which are related to negative outcomes or bad luck. The overall reliability of the scale is .83 .

Belief in good luck scale. The scale developed by Darke and Freedman (1997) measure ones belief in good luck. Luck was perceived to be a fairly constant characteristic which favored few but not the others. The scale consists of 12 items and participants have to specify their responses on a 6-point rating scale. A higher score on the scale indicated a greater belief in good luck. The reliability of the scale is .85 .

Magical ideation scale. Eckblad and Chapman (1983) developed Magical Ideation Scale which had 30 true and false items. Magical ideation is considered as having erroneous beliefs which stem out of magical thinking. Magical ideation is a symptom of schizophrenia proneness. High scores on magical ideation scale point to a predisposition to psychosis. The Magical Ideation scale had a reliability of .82 for males and .85 for females.

\section{Results}

Confirmatory factor analysis was done to check the fit of Superstitious Beliefs Scale identified from EFA in study 1, using the twentieth version of AMOS. First, we examined a single factor model where all the 17- items were mapped on one latent superstitious beliefs factor. Next, we tested the six-factor model from EFA wherein all the items loaded on six latent factors (Figure 1). These factors were correlated. 
Table 3 shows the summary of results for unidimensional model and the six factor models. Results indicate support for hierarchical model as all the six dimensions significantly loaded on the higher order superstitious beliefs structure. Recommended cut off values by Schermelleh-Engel, Moosbrugger, and Müller (2003) were applied to judge the fit of measurement model. All the fit indices indicate a poor fit for one factor model: $\chi^{2}(119, \mathrm{~N}=483)=1052.68, \mathrm{p}=.00$; RMSEA $=.12(90 \%$ CI of RMSEA $=.121-.135) ;$ SRMR $=.07 ; \mathrm{CFI}=.74 ;$ and TLI $=.71$. The hierarchical model fits the data extremely well: $\chi^{2}(113, \mathrm{~N}=483)=283.43, \mathrm{p}=.00$; RMSEA $=.56(90 \% \mathrm{CI}$ of RMSEA = .048-.064); $\mathrm{SRMR}=.04 ; \mathrm{CFI}=.95 ;$ and $\mathrm{TLI}=.94$. Factor loadings were in between 0.20 and $0.96($ Mean $=0.69$, $\mathrm{SD}=0.18$ ). Root mean square error of approximation (RMSEA) index between o and .05 signifies a very good model fit, values ranging amid .05 and .08 is considered good fit, values amid .08 and .10 is poor fit and above .10 is an indication of bad fit (Byrne, 2012). Standardized Root Mean Square Residual (SRMR) index between o and .05 is considered as a suggestion of good fit, and its value between .05 and .10 as an acceptable fit. Tucker-Lewis (TLI) and Comparative Fit indices above .90 are considered as indicating acceptable fit. Based on all the above indices the model explored in CFA is considered a very good fit than single factor model.

Table 4 gives the internal consistency coefficient for Superstitious Beliefs Scale in Study 2. The overall scale showed an alpha value of .89 indicating high reliability. The internal consistencies of all the six factors were computed. The alpha value for the factor of Popular Beliefs is .8o, Belief in Good luck is .74, Belief in Bad Luck is .80, Belief that Luck can Change is.55, Personal Superstitions is .8o and Social Superstitions is .83. All the factors showed high internal consistencies except for Belief that Luck can Change.

To corroborate the construct validity of the scale, we tried to establish the convergent validity. For this purpose, we considered the correlations between Superstitious Beliefs Scale and already established measures of Belief in Good Luck Scale (Drake \& Freedman, 1997), Belief in Superstition Scale (Wiseman \& Watt, 2004) and Revised Belief in superstition Scale (Fluke et al., 2014). The means, standard deviations, and correlations are presented in Table 5. As assumed the total score of Superstitious Beliefs Scale is positively correlated with Belief in superstition scale $(\mathrm{r}$ $(158)=.60, p<0.01)$, Revised Belief in Superstition Scale $(\mathrm{r}(158)=.62, \mathrm{p}<0.01)$ and The Belief in Good Luck $(\mathrm{r}(158)=.61, \mathrm{p}<0.01)$. All the results were statistically significant. At the dimensional level, Belief in Good Luck, Belief in Bad Luck dimensions of Superstitious Beliefs Scale were positively correlated with Good Luck scale $(\mathrm{r}(158)=.59, \mathrm{p}<0.01)$ and Bad Luck scale $(\mathrm{r}(158)=.53$, $\mathrm{p}<0.01)$ of Revised Belief in Superstitious Scale. The dimensions were also correlated with Positive Superstitions $(\mathrm{r}(158)=.46, \mathrm{p}<0.01)$ and Negative Superstitions subscales $(\mathrm{r}(158)=.45, \mathrm{p}<0.01)$ of Wisemans's Belief in Superstition Scale. The Belief in Good Luck Dimension was positively correlated with Drake and Freedman's Belief in Luck scores. $(\mathrm{r}(158)=.62, \mathrm{p}<0.01)$. The overall Superstitious Belief scores were also positively correlated with Magical Ideation ( $\mathrm{r}(158)=.45, \mathrm{p}<$ 0.01).

\section{Discussion}

The results from Study 2 demonstrate that the proposed hierarchical six-factor structure is substantially better fit than the alternative single factor structure in a new sample. The internal consistency for the scale in Study 2 was also very high. The findings from the study demonstrate a psychometrically sound multidimensional measure of assessing superstitious beliefs. The factor loadings were moderate to high on all dimensions. 
The results of Studies 1 and 2 together present evidence that the Superstitious Beliefs Scale is psychometrically sound. The scale has a robust factor structure and very high degree of internal consistency. The derivative factors make conceptual sense. Three of the factors validate the framework proposed by Weisman and Watt (2004) and furthered by Fluke et al., (2014). The other three factors expand the knowledge of superstitions and contribute towards extended understanding of superstitions embedded in prevalent cultural context. The subsequent step was to demonstrate the convergent and validity of the scale.

The construct validity of the instrument was established by analyzing information from item analysis, factor analysis, and convergent validity and divergent validity indices. The results from study 1 established the factorial validity of the scale. In the present study, construct validity was established by its anticipated performance on scales of convergent validity against theoretically related constructs.

The total score of Superstitious Beliefs Scale was significantly positively correlated with total scores of three other existing measures of superstitious beliefs. The convergence with scores on other superstition measures is in accordance with the overlap of conceptualization of superstitious beliefs in terms of beliefs around good and bad luck (Fluke et al., 2014; Wiseman and Watt, 2004). Furthermore, the dimensions of Superstitious Beliefs Scale strongly correlated with their corresponding designated dimensions in the three scales. Superstitious belief scores were also correlated with Magical Ideation.

\section{General Discussion}

The present research introduced a new self-report instrument to measure superstitious beliefs relevant to Indian context over two studies. Superstitious practices are predominantly embedded strongly within an individual's cultural context thereby making it important to explore the use of existing measures across locations. The Superstitious Beliefs Scale developed in the present study builds on the existing framework proposed initially by Wiseman \& Watt (2004) and refined further by Fluke et al., (2014). The 17-item scale comprises of six distinct dimensions namely Popular Beliefs, Beliefs in Good Luck, Beliefs in Bad Luck, Personal Superstitious Behavior, Social Superstitious Behavior and Belief in Change of Luck. The scale retains the three dimensions of The Belief in Superstitions Scale by Fluke et al., (2014) although there are changes in few items from the original scale. The three additional dimensions of the new scale were Popular Beliefs, Individual Superstitious Behaviors, and Social Superstitious Behaviors. The dimension of Popular Belief reflects specific superstitious beliefs which are widely believed in society. It is evident from the items under this dimension, that the prevalent specific superstitions in the present scale are different from the items on popular beliefs in western societies (Wiseman \& Watt, 2004; Darke \& Freedman, 1997). This also justifies our goal of developing a measure which is more relevant in Indian context.

Most of the existing scales of superstitious beliefs were developed in individualistic societies. The role of family and community in the beliefs held by individuals becomes important in a collectivistic society (Markus \& Kitayama, 1991). The dichotomous explanation of culture was given by Hofstede (1980). Triandis and Suh (2002) advocate that, individuals in collectivist cultures consider the cultural norms and social obligations as important and stable. The individual needs to strive to fit into the environment. Whereas, in the individualistic cultures the person is considered stable and it is the environment which needs to change to fit the individual. However, with the advent of globalization and the economic changes which go along with it in India, there is a pressure 
to move towards Individualism (Shah, 2009). As a result Indians are leaning towards a combination of collectivistic and individualistic context. The Superstitious beliefs in this research are considered a result of the interaction of independent and interdependent natures of self. The dimensions of Personal Superstitious Behaviors and Social Superstitious Behaviors reflect the beliefs one holds due to personal experiences and due to prevalent social norms.

The Superstitious Beliefs Scale developed is reliable and the six-factor structure established across two studies is distinct. The dimensions are also shown to be reliable across two studies. The test- retest reliability is also high. The six-factor solution from the exploratory factor analysis and confirmatory factor analysis substantiates the association of the six dimensions to the proposed theoretical framework of superstitious beliefs ensuring the construct validity (DeVellis, 2003). The construct validity of the scale was also established through convergent validity indices. Good associations with existing measures of superstitious beliefs indicate the support for the same. The findings of the study broaden the existing theoretical understanding on superstitions and provide a novel framework by contextualizing superstitions in culture. However, the scale cannot be relevant for all cultures. The Superstitious Beliefs Scale could be a helpful model for future scale development in other similar cultures.

\section{Limitations}

The study involved university students as its participants thereby limiting its generalizability and suggests a need for verifying the applicability of scale for other age groups. The sample in the studies was also slightly skewed as the majority of participants were female. This skewness is evident as the participants were from the deanery of humanities and social sciences and more number of women seeks admission in these courses at University level than men. The study also did not include an attempt at the concurrent or predictive validity of the scale, which would have strengthened the validity of the scale.

\section{Conclusions}

Regardless of the limitations, Superstitious Beliefs Scale displays strong proof of psychometric strength. It also demonstrates the enhancement in contextual relevance and ability to explore multiple dimensions of beliefs and behaviors as compared to prior scales. Though superstitions are widely prevalent in all the cultures, Superstitious Beliefs Scale will serve as an effective instrument to scientifically examine them in India.

\section{References}

Aarnio, K., \& Lindeman, M. (2005). Paranormal beliefs, education, and thinking styles. Personality and individual differences, 39(7), 1227-1236. doi: 10.1016/j.paid.2005.04.009

Ang, S. H., Lai, W. K., \& Leong, S. M. (2014). The effects of superstition on choice and latency. Psychology and Marketing, 31(12), 1074-1083. doi: 10.1002/mar.20754

Antipov, E. A., \& Pokryshevskaya, E. B. (2015). Are buyers of apartments superstitious? Evidence from the Russian real estate market. Judgment and Decision Making, 10(6), 590-592. 
Archetti, E. P. (1999). Masculinities: Football, polo and the tango in Argentina. Oxford: Berg.

Barkoukis, V., Perkos, S., \& Kokkinopoulos, S. (2011). Being superstitious in sports: Effect of superstitious beliefs on athletes' cognitive and affective responses. University of Thessaly Institutional Repository.

Barro, R. J., \& McCleary, R. M. (2002). Religion and political economy in an international panel. NBER Working Paper Series, No. 8931: Cambridge, MA.

Beck, J., \& Forstmeier, W. (2007). Superstition and belief as inevitable by-products of an adaptive learning strategy. Human Nature, 18(1), 35-46.

Beck, R., \& Miller, J. P. (2001). Erosion of belief and disbelief: Effects of religiosity and negative affect on beliefs in the paranormal and supernatural. The Journal of Social Psychology, 14, 277-287.

Ben-Yehuda, N. (1985). Deviance and moral boundaries: Witchcraft, the occult, science fiction deviant sciences and scientists. Chicago: University of Chicago Press.

Birrell, S. (1981). Sport as ritual: Interpretations from Durkheim to Goffman. Social Forces, 6o(2), 354-376. doi: $10.2307 / 2578440$

Bleak, J. L., \& Frederick, C. M. (1998). Superstitious behavior in sport: Levels of effectiveness and determinants of use in three collegiate sports. Journal of Sport Behavior, 21(1), 1-15.

Block, L., \& Kramer, T. (2009). The effect of superstitious beliefs on performance expectations. Journal of the Academy of Marketing Science, 37(2), 161-169. doi: 10.1007/s11747-0o8-0116-y

Blum, S. H. (1976). Some aspects of belief in prevailing superstitions. Psychological Reports, 38(2), 579-582.

Botha, F. (2013). Stock returns and Friday the 13th effect in five African countries. African Review of Economics and Finance, 4(2), 247-253.

Brevers, D., Dan, B., Noel, X., \& Nils, F. (2011). Sport superstition: Mediation of psychological tension on non-professional sportsmen's superstitious rituals. Journal of Sport Behavior, 34(1), 3-24.

Buhrmann, H. G., \& Zaugg, M. K. (1981). Superstitions among basketball players an investigation of various forms of superstitious belief and behavior among competitive basketballers at the junior high school to university level. Journal of Sport Behavior, 4(4), 163.

Burger, J., \& Lynn, A.L. (2005). Superstitious behavior among American and Japanese professional baseball players. Basic and Applied Social Psychology, 27(1), 71-76.

Byrne, B. M. (2012). Structural equation modelling with Mplus: Basic concepts, applications, and programming. New York: Taylor \& Francis Group.

Campbell, C. (1996). Half-belief and the paradox of ritual instrumental activism: a theory of modern superstition. British Journal of Sociology, 47, 151-166.

Carlson, B. D., Mowen, J. C., \& Fang, X. (2009). Trait superstition and consumer behavior: Reconceptualization, measurement, and initial investigations. Psychology \& Marketing, 26(8), 689-713. doi: 10.1002/mar.20295

Carmines, E. G., \& Zeller, R. A. (1979). Reliability and Validity Assessment. Beverly Hills, California: Sage Publications.

Chadda, R., \& Deb, K. S. (2013). Indian family systems, collectivistic society and psychotherapy. Indian Journal of Psychiatry, 55(2), 299-209. doi: 10.4103/0019-5545.105555

Czech, D. R., Wrisberg, C., Fisher, L., Thompson, C., \& Hayes, G. (2004). The experience of Christian prayer in sport - An Existential Phenomenological Investigation. Journal of Psychology and Christianity, 2, 1-19. 
Dag, I. (1999). The relationships among paranormal beliefs, locus of control and psychopathology in a Turkish college sample. Personality and Individual Differences, 26, 723-737.

Damisch, L., Stoberock, B., \& Mussweiler, T. (2010). Keep your fingers crossed! How superstition improves performance. Psychological Science, 21(7), 1014-1020. doi: 10.1177/095679761037263

Darke, P. R., \& Freedman, J. L. (1997). The belief in good luck scale. Journal of Research in Personality, 31(4), 486-511.

Delacroix, E., \& Guillard, V. (2008). Understanding, defining and measuring the trait of superstition. Paper presented at Selected Proceedings of the IAREP/SABE 2008 Conference at LUISS, Rome. Retrieved from http://basepub.dauphine.fr/bitstream/

DeVellis, R. F. (1991). Scale Development: Theory and Applications. Newbury Park, California: Sage Publications.

De Vellis, R. F. (2003). Scale Development: Theory and Applications (2nd ed.). Thousand Oaks, CA: Sage Publications.

DeVellis, R. F. (2012). Scale Development: Theory and Applications (3rd ed.). Newbury Park, CA: Sage.

Dresslar, F. B. (1907). Superstition and education (Vol. 5). Harvard University: The University Press.

Eckblad, M., \& Chapman, L. J. (1983). Magical ideation as an indicator of schizotypy. Journal of Consulting and Clinical Psychology, 51, 215-225.

Emadi, H. (2005). Culture and customs of Afghanistan. USA: Greenwood Publishing Group, Inc.

Farooq, A., \& Kayani, A. K. (2012). Prevalence of superstitions and other supernatural in rural Punjab: A sociological perspective. A Research Journal of South Asian Studies, 27(2), 335-344.

Fidrmuc, J., \& Tena, J. D. (2015). Friday the 13th: The empirics of bad luck. KYKLOS, 68(3), 317-334.

Field, A. (2009). Discovering statistics using SPSS (3rd ed.). Thousand Oaks, California: Sage Publications.

Fluke, S. M., Webster, R. J., \& Saucier, D. A. (2014). Methodological and theoretical improvements in the study of superstitious beliefs and behaviour. British Journal of Psychology, 105(1), 102-126. doi: 10.1111/bjop.12008

Foster, R. S., \& Kokko, H. (2009). The evolution of superstition and superstition-like behaviour. Proceedings of the Royal Society: Biological Sciences, 276(1654), 31-37. doi: 10. 1098/rspb.2008.0981

Frotin, N. M., Hill, A. J., \& Huang, J. (2014). Superstition in the housing market. Economic Inquiry, 52(3), 974-993. doi: 10.1111/ecin.12066

Fu, S., \& Viard, B. (2011). The effect of Beijing's Dribing restrictions on pollution and economic activity. (Unpublished manuscript), Cheung Kong Graduate School.

Gallup Poll. (2005). The Gallup Poll: Public Opinion. Retrieved from https://books.google.co.in/books/about/The_Gallup_Poll.html?id=WOugopzW6_IC\&redir_esc=y

Gallup Poll. (1996). The Gallup Poll: Public Opinion. Retrieved from http://news.gallup.com/poll/2440/onefour-americans-superstitious.aspx

Hanks, L., Zhang, L., \& McGinley, S. (2016). Unconditioned superstition and sports bar fans. Journal of Hospitality Marketing \& Management, 25, 113-131. doi: 10.1080/19368623.2014.987417

Haselton, M. G., \& Nettle, D. (2006). The paranoid optimist: An integrative evolutionary model of cognitive biases. Personality and Social Psychology Review, 10(1), 47-66. doi: 10.1207/s15327957pspr10o1_3

Hinkin, T. R., Tracey, J. B., \& Enz, C. A. (1997). Scale construction: Developing reliable and valid measurement instruments. Journal of Hospitality $\mathcal{E}$ Tourism Research, 21(1), 100-120. 
Hirshleifer, D., Jian, M., \& Zhang, H. (2011). Does Superstition Affect Stock Prices? Financial Management Association Annual Conference, Annual Meeting of the American Accounting Association, Denver, CO.

Hoffman, S. J. (2010). Prayer out of bounds. In Good Game: Christianity and the Culture of Sports. Waco, TX: Baylor University Press.

Hofstede, G. (1980). Culture's consequences: International differences in work-related values. Beverly Hills, CA: Sage

Hutcheson, G. D., \& Sofroniou, N. (1999). The multivariate social scientist: Introductory statistics using generalized linear models. Thousand Oaks, CA: Sage.

Irwin, H. J. (1993). Belief in the paranormal: A review of the empirical literature. Journal of the American Society for Psychical Research, 87(1), 1-39.

Jahoda, G. (1968). Scientific training and the persistence of traditional beliefs among West African university students. Nature, 220, 1356. doi:10.1038/2201356ao

King, R. B., \& McInerney, D. M. (2012). Including social goals in achievement motivation research: Examples from the Philippines. Online Readings in Psychology and Culture, 5(3). doi: 10.9709/2307-0919.1104

Koenig, H. G., \& Büssing, A. (2010). The Duke University Religion Index (DUREL): A five-item measure for use in epidemiological studies. Religions, 1, 78-85. doi:10.3390/rel1010078

Kolb, R. W., \& Rodriguez, R. J. (1987). Friday the thirteenth: 'Part VII'-A note. The Journal of Finance, 42(5), 1385-1387. doi: $10.2307 / 2328534$

Kramer, T., \& Block, L. (2008). Conscious and nonconscious components of superstitious beliefs in judgment and decision making. Journal of Consumer Research, 34(6), 783-793. doi: 10.1086/523288

Kramer, T., \& Block, L. (2011). Nonconscious effects of peculiar beliefs on consumer psychology and choice. Journal of Consumer Psychology, 21(1), 101-111. https://doi.org/10.1016/j.jcps.2010.09.009

Kreider, A. J. (2003). Prayers for assistance as unsporting behavior. Journal of the Philosophy of Sport, 30(1), 17-25. doi: 10.108o/00948705.2003.9714557

Lawrence, I. (2005). The emergence of 'sport and spirituality' in popular culture. The Sport Journal, 8(2), 1-5.

Levitt, E. E. (1952). Superstitions: Twenty-five years ago and today. The American Journal of Psychology, 65(3), 443-449.

Lewis, J. M., \& Gallagher, T. J. (2001). The salience of Friday the 13th for college students. College Student Journal, 35, 216-222.

Lindeman, M., \& Saher, M. (2007). Vitalism, purpose and superstition. British Journal of Psychology, 98(1), 33-44. doi: 10.1348/000712606X101808

MacDonald, W. L. (1995). The effects of religiosity and structural strain on reported paranormal experiences. Journal for the Scientific Study of Religion, 34(3), 366-76. doi: 10.2307/1386885

Malinowski, B. (1927). Coral gardens and their magic. London: Routledge and Kegan.

Malinowski, B. (1948). Magic, science and religion. Garden City: Doubleday.

Maranise, A. M. J. (2013). Superstition and religious ritual: An examination of their effects and utilization in sport. The Sport Psychologist, 27(1), 83-91. doi: 10.1123/tsp.27.1.83

Markus, H., \& Kitayama, S. (1991). Culture and the self: Implications for cognition, emotion, and motivation. Psychological Review, 98(2), 224-53.

McGill, D. (1983). Cultural concepts for family therapy. In: Hansen J, Falicov C, (Ed.). Cultural perspectives in family therapy: The family therapy collections. Rockville, MD: Aspen. pp. 108-21. 
Miller, T. (2008). Sport \& spirituality: A comparative perspective. The Sport Journal, 11(3), 1-9.

Mowen, J. C., \& Carlson, B. (2003). Exploring the antecedents and consumer behaviour consequences of the trait of superstition. Psychology and Marketing, 20(12), 1045-1065.

Mullick, M. S. I., Khalifa, N., Nahar, J. S., \& Walker, D. W. (2013). Beliefs about Jinn, black magic and evil eye in Bangladesh: The effects of gender and level of education. Mental Health, Religion $\mathcal{E}$ Culture, 16(7), 719-729. doi: 10.108o/13674676.2012.717918

Mundada, N. D. (2013). Locus of control and superstitions. International Journal of Humanities and Social Science Invention, 2-6.

Murray, M. A., Joyner, A. B., Burke, K. L., Wilson, M. J., \& Zwald, A. D. (2005). The relationship between prayer and team cohesion in collegiate softball teams. Journal of Psychology and Christianity, 24, 233-239.

Ofori, P. K., Biddle S., \& Lavallee, D. (2012).The role of superstition among professional footballers in Ghana. Athletic Insight, 4(2), 115-126.

Ofori, P. K., Tod, D., \& Lavallee, D. (2017). Predictors of superstitious beliefs. Journal of Psychology in Africa, $27(1), 1-12$.

Orenstein, A. (2002). Religion and paranormal belief. Journal for the Scientific Study of Religion, 41, 301-311.

Otis, L. P., \& Alcock, J. E. (1982). Factors affecting extraordinary belief. The Journal of Social Psychology, 118, $77-85$.

Pallant, J. (2007). SPSS Survival Manual (3rd ed.). Buckingham: Open University Press.

Parida, G. (1962). Superstitions among college students in India. Journal of Social Psychology, 57, 3-10. doi:10.1080/00224545.1962.9710898

Peltzer, K. (2003). Magical thinking and paranormal belief among secondary and university students in South Africa. Personality and Individual Differences, 35, 1419-1426.

Peng, K., \& Nisbett, R. E. (1999). Culture, dialectics, and reasoning about contradiction. American Psychologist, 54(9). http://dx.doi.org/10.1037/0003-066X.54.9.741

Peterson, C. (1978). Locus of control and belief in self-oriented superstitions. The Journal of Social Psychology, 105(2), 305-306. doi: 10.1080/00224545.1978.9924131

Presson P. K., \& Benassi, V. A. (1996). Illusion of control: A meta-analytic review. Journal of Social Behavior and Personality, 11(3), 493-510.

Price, J. L. (2009). Playing and praying, sport and spirit: The forms and functions of prayer in sports. International Journal of Religion and Sport, 1, 55-80.

Ramezani, K., Ramezani, M., \& Ramezani, Z. (2016). Comparison of the trend of superstition in educated academics and commons Kohgiluyeh and Boyer-Ahmad. International Journal of Humanities and Cultural Studies, 496-510.

Ranieri, A. Y. (2015). How luck and fortune shape risk-taking behaviors (Master's Thesis). University of South Florida, South Florida.

Raubenheimer, J. (2004). An item selection procedure to maximize scale reliability and validity. SA Journal of Industrial Psychology, 30(4), 59-64.

Saenko, I. V. (2005). The superstition of today's college students. Russian Education and Society, 47, 76-89.

Schermelleh-Engel, K., Moosbrugger, H., \& Müller, H. (2003). Evaluating the fit of structural equation models: Tests of significance and descriptive goodness-of-fit measures. Methods of Psychological Research Online, 8(2), 23-74. 
Shah, G. (2009). The impact of economic globalization on work and family collectivism in India. Journal of Indian Business Research, 1.(2): 95-118.

Shrivastav, M., \& Kotnala, A. (2015). Psycho-social factors contributing to superstitious behavior: Literature review. International Journal of Research-Granthaalayah, 3(5), 42-47.

Shum, M., Sun, W., \& Ye, G. (2014). Superstition and "lucky" apartments: Evidence form transaction-level data. Journal of Comparative Economics, 42, 109-117. doi: 10.1016/j.jce.2013.10.001

Stanke, A. (2004). Religiosity, locus of control, and superstitious belief. Journal of Undergraduate Research, 7(1), 1-5.

Stark, R., \& Bainbridge, W. S. (1980). Toward a theory of religion: Religious commitment. Journal for the Scientific Study of Religion, 19, 114-128.

Stones, M. J., Kozma, A., Hirdes, J., Gold, D., Arbuckle, T., \& Kolopack, P. (1996). Short Happiness and Affect Research Protocol (SHARP). Social Indicators Research, 37(1), 75-91. doi:10.1007/BFoo300270

Storch, E. A., McNamara, J., Jordan, C., Marien, W. E., Jacob, M. L., Murphy, T. K., ...Geffken, G. R. (20o8). Associations between miscellaneous symptoms and symptom dimensions in adults with obsessivecompulsive disorder. Anxiety, Stress, E Coping, 21, 199-212. doi: 10.1080/10615800701885369

Subbotsky, E. (2004). Magical thinking-Reality or illusion? The Psychologist, 17(6), 336-339.

Sumaranjitha, L., \& Sreedhar, K. P. (1992). Unsubstantiated beliefs in adolescent girls. The Creative Psychologist, 4, 35-40.

Tobacyk, J. J. (1984). Paranormal belief and college grade point average. Psychological Reports, 54, 217-218.

Tobacyk, J., \& Milford, G. (1983). Belief in paranormal phenomena: Assessment instrument development and implications for personality functioning. Journal of Personality and Social Psychology, 44, 10291037.

Tobacyk, J., \& Shrader, D. (1991). Superstition and self-efficacy. Psychological Reports, 68(3). 1387-1388.

Todd, M., \& Brown, C. (2003). Characteristics associated with superstitious behavior in track and field athletes: Are there NCAA divisional level differences?. Journal of Sport Behavior, 26(2), 168.

Torgler, B. (2003). It is about believing: Superstition and religiosity. Center for Research in Economics, Management and the Arts.

Torgler, B. (2007). Determinants of superstition. The Journal of Socio- Economics, 36, 713-733. doi: 10.1016/j.socec.2007.01.007

Triandis, H.C. \& Suh, E.M. (2002), Cultural influences on personality", Annual Review of Psychology, Vol. 53, pp. 133-6o.

Vyse, S. A. (1997). Believing in magic: The psychology of superstition. New York, NY: Oxford University Press.

Watson, N.J., \& Czech, D.R. (2005). The use of prayer in sport: Implications for sport psychology consulting. Journal of Sport Psychology, 7(4), 26-31.

Wiseman, R., \& Watt, C. (2004). Measuring superstitious belief: Why lucky charms matter. Personality and Individual Differences, 37(8), 1533-1541. doi:10.1016/j.paid.2004.02.009

Yong, A. G., \& Pearce, S. (2013). A beginner's guide to factor analysis: Focusing on exploratory factor analysis. Tutorials in Quantitative Methods for Psychology, 9(2), 79-94.

Zhang, Y., Risen, J. L., \& Hosey, C. (2013). Reversing one's fortune by pushing away bad luck. Journal of Experimental Psychology, 143(3), 1171-1184. doi: 10.1037/a0034023 


\section{Appendix}

\section{Tables}

Table 1

KMO and Bartlett's Tests of Sphericity Results

\begin{tabular}{lrr}
\hline Kaiser-Meyer-Olkin Measure of Sampling Adequacy. & .93 \\
& Approx. Chi-Square & 14362.112 \\
Bartlett's Test of Sphericity & Df & 190 \\
& Sig. & $.00^{*}$ \\
\hline
\end{tabular}

Note. ${ }^{*} p<.01$

Table 2

Items, Means, Standard deviations, Item analysis indices, internal consistency and factor loadings of SBS

\begin{tabular}{l}
\hline \\
\end{tabular}


When given an option to choose a number, I tend to go with the

lucky one

A good luck charm can change the outcome of chance events

I actively seek out good luck

I believe touching wood would bring good luck

Factor 3: Belief in Bad Luck

It is important to avoid unlucky actions

I avoid unlucky situations

Number 13 is considered inauspicious

When I come across a bad omen, I would rather delay my actions

Factor 4: Belief that Luck can Change

Trying to change your luck is a waste of time

I often attempt to change my luck

Doing things a certain way can change your luck, for good or bad

Factor 5: Personal superstitious Behaviour

I follow certain rituals unrelated to the task that had been followed by positive outcomes on previous occasions

I believe that I can change the outcome of events if I do certain rituals If a certain action/ behaviour though unrelated to the task, had helped me through a situation, I would repeat it as I believe that it would lead to positive outcomes

Factor 6: Social Superstitious Behaviour

I follow certain good luck/bad luck rituals just because my family expects me to follow them

I practice certain good luck/bad luck rituals because they are prevalent in my community

$\begin{array}{lllllll}2.97 & 1.22 & .51 & .59 & .47 & .57 & .833 \\ & & & & & & \\ 2.07 & 1.02 & .70 & .80 & .67 & .81 & .655 \\ 2.65 & 1.06 & .62 & .66 & .58 & & .584 \\ 2.36 & 1.19 & .63 & .76 & .59 & & .517\end{array}$

$\begin{array}{lllllll}2.36 & 1.01 & .58 & .65 & .55 & .89 & 837\end{array}$

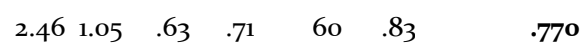

$\begin{array}{llllll}1.90 & 1.00 & .45 & .56 & .41 & .58\end{array}$

$\begin{array}{lllll}2.02 & 1.01 & .70 & .62 & .60\end{array}$

$\begin{array}{lllllll}2.64 & 1.19 & .26 & .38 & .31 & .20 & \end{array}$

$\begin{array}{llllll}2.40 & 1.10 & .52 & .55 & .48 & .72\end{array}$

$\begin{array}{lllllll}2.65 & 1.18 & .57 & .64 & .52 & .35 & .439\end{array}$

$\begin{array}{llllll}2.33 & 1.12 & .63 & .74 & .60 & .72\end{array}$

.856

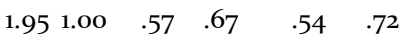

.792

$\begin{array}{llllll}2.93 & 1.13 & .57 & .63 & 53 & .72\end{array}$

.696

Note. SD - Standard Deviation, ITC-Item total correlations, IDI - Item discrimination index, CITC -Corrected Item total correlation, $\alpha$ - Cronbach's Internal Consistency Coefficient, CFA - Confirmatory Factor Analysis loadings;

Factor loadings of items in final version based on EFA are in bold,

Table 3

Confirmatory Factor Analysis results for Superstitious Beliefs Scale

\begin{tabular}{lcccccccc}
\hline Model & $\mathrm{df}$ & $\chi^{2}$ & RMSEA & CMIN/df & CFI & TLI & SRMR & $P$ \\
\hline One Factor Model & 119 & 1052.68 & .12 & 8.84 & .74 & .71 & .077 & .00
\end{tabular}


$\begin{array}{lllllllll}\text { Six Factor Model } & 113 & 283.43 & .56 & 2.50 & .95 & .94 & .046 & .00\end{array}$ Note. RMSEA= Root Mean Square Error of Approximation, CFI =Comparative Fit Index, TLI =Tucker Lewis Index, SRMR= Standardized Root Mean Square Residual

Table 4

Reliability Analysis of SBS

$\alpha$

Study 1 Study 2

\begin{tabular}{lcc}
\hline Factor 1: Popular Beliefs & .78 & .80 \\
Factor 2: Belief in Good Luck & .74 & .74 \\
Factor 3: Belief in Bad Luck & .70 & .80 \\
Factor 4: Belief that Luck can Change & .64 & .55 \\
Factor 5: Personal Superstitious Behaviour & .73 & .80 \\
Factor 6: Social Superstitious Behaviour & .82 & .83 \\
Overall Scale $\alpha$ & .87 & .89 \\
Test Retest Reliability & .90 & \\
\hline
\end{tabular}

Table 5

Means, Standard Deviations and correlations of superstitious beliefs and indicators of convergent validity in study 2

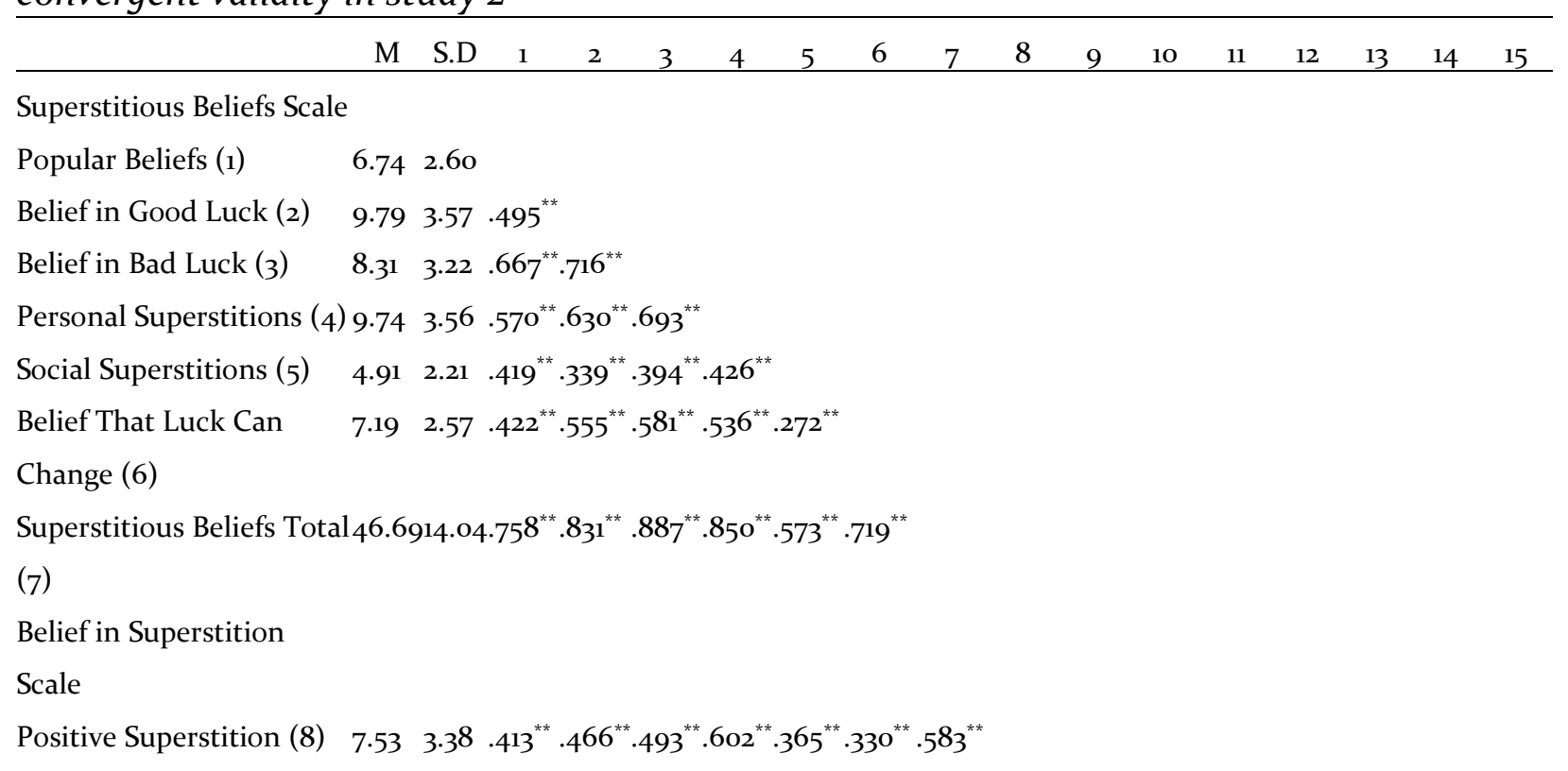


19 | Development and Validation of Superstitious Beliefs Scale

Negative Superstition (9) $4.262 .40 \cdot 371^{* *} \cdot 358^{* *} \cdot 456^{* *} \cdot 330^{* *} \cdot 081 \quad .246^{* *} \cdot 409^{* *} \cdot 414^{* *}$

Belief in Superstition

$11.794 .85 \cdot 467^{* *} \cdot 497^{* *} \cdot 564^{* *} \cdot 577^{* *} \cdot 291^{* *} \cdot 349^{* *} \cdot 603^{* *} \cdot 893^{* *} \cdot 780^{* *}$

Total (10)

Revised Belief in

Superstition Scale

RBSS: Bad Luck (11)

$16.136 .24 \cdot 370^{* *} \cdot 683^{* *} \cdot 534^{* *} \cdot 564^{* *} \cdot 210^{* *} \cdot 474^{* *} \cdot 632^{* *} \cdot 369^{* *} \cdot 403^{* *} \cdot 453^{* *}$

RBSS:Good Luck (12)

$16.415 \cdot 71 \cdot 516^{* *} \cdot 590^{* *} \cdot 614^{* *} \cdot 554^{* *} \cdot 298^{* *} \cdot 432^{* *} \cdot 658^{* *} \cdot 567^{* *} \cdot 339^{* *} \cdot 558^{* *} \cdot 631^{* *} 1$

RBSS: Change Luck (13)

23.4413.19.042 111 .068 . 106 .075 - 007 .090 $284^{* *}-.061 .165^{*} .143 \quad .333^{* *}$

Total: RBSS (14)

$55 \cdot 9813 \cdot 19 \cdot 415^{* *} \cdot 623^{* *} \cdot 546^{* *} \cdot 549^{* *} \cdot 259^{* *} \cdot 409^{* *} \cdot 620^{* *} \cdot 534^{* *} \cdot 313^{* *} \cdot 522^{* *} \cdot 804^{* *} \cdot 865^{* *} \cdot 612^{* *}$

Belief in Luck Scale (15)

$37.619 .96 \cdot 351^{* *} \cdot 625^{* *} \cdot 528^{* *} \cdot 544^{* *} \cdot 287^{* *} \cdot 428^{* *} \cdot 611^{* *} \cdot 482^{* *} \cdot 358^{* *} \cdot 509^{* *} \cdot 525^{* *} \cdot 524^{* *} \cdot 227^{* *} \cdot 566^{* *}$

Magical Ideation (16)

$10.094 \cdot 34.265^{* *} \cdot 382^{* *} \cdot 420^{* *} \cdot 443^{* *} \cdot 265^{* *} \cdot 285^{* *} \cdot 452^{* *} \cdot 353^{* *} \cdot 088 \cdot 287^{* *} \cdot 342^{* *} \cdot 458^{* *} \cdot 232^{* *} \cdot 453^{* *} \cdot 380^{* *}$

Note. RBSS- Revised Belief in Superstition Scale;

${ }^{*} \mathrm{p}<0.05 ;{ }^{* *} \mathrm{p}<0.01$ 



\section{Figures}

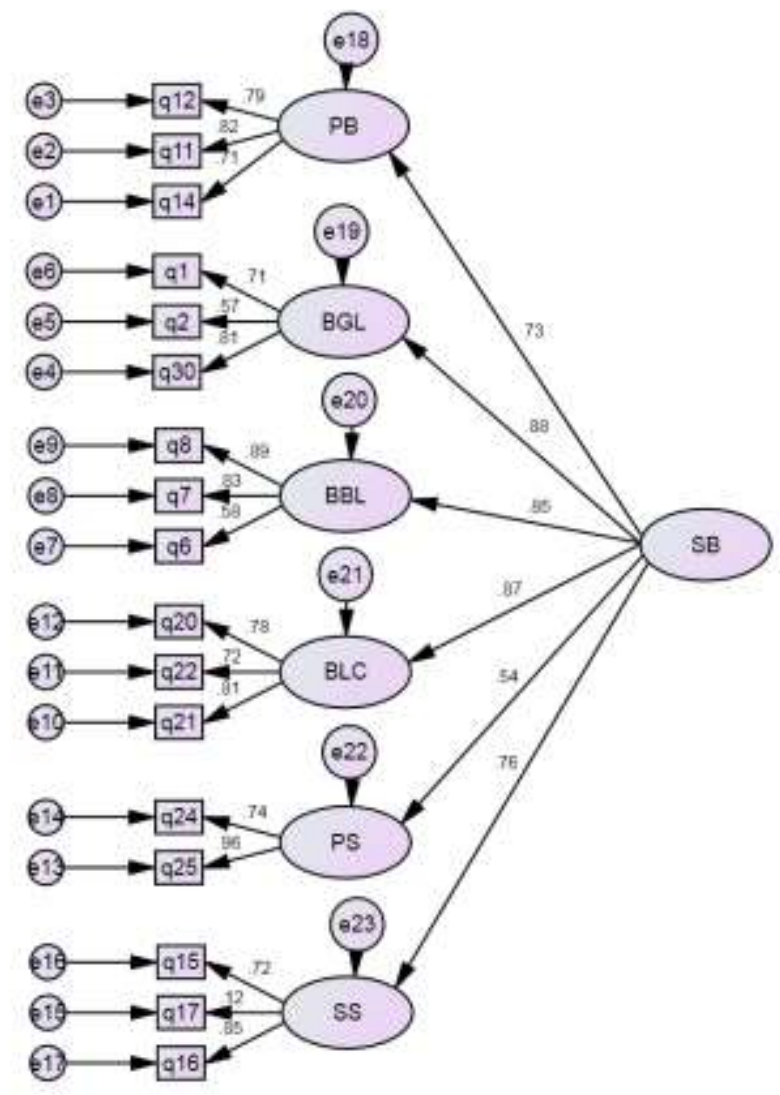

Figure 1. Confirmatory Analysis results for the hierarchical model.

SB-Superstitious Beliefs, PB-Popular Beliefs, BGK - Belief in Good Luck, BBL-Belief in Bad Luck, BLC-Belief that Luck can Change, PS-Personal Superstitions, SS-Social Superstitions 